\title{
Eubulides as a 20th-century semanticist
}

\author{
Pieter A.M. Seuren \\ Max Planck Institute for Psycholinguistics, P.O. Box 310, 6500 AH Nijmegen, The Netherlands
}

Accepted 2 December 2003

\begin{abstract}
It is the purpose of the present paper to highlight the figure of Eubulides, a relatively unknown Greek philosopher who lived $\pm 405-330 \mathrm{BC}$ and taught at Megara, not far from Athens. He is mainly known for his four paradoxes (the Liar, the Sorites, the Electra, and the Horns), and for the mutual animosity between him and his younger contemporary Aristotle. The Megarian school of philosophy was one of the main sources of the great Stoic tradition in ancient philosophy. What has never been made explicit in the literature is the importance of the four paradoxes for the study of meaning in natural language: they summarize the whole research programme of 20th century formal or formally oriented semantics, including the problems of vague predicates (Sorites), intensional contexts (Electra), and presuppositions (Horns). One might say that modern formal or formally oriented semantics is essentially an attempt at finding linguistically tenable answers to problems arising in the context of Aristotelian thought. It is a surprising and highly significant fact that a contemporary of Aristotle already spotted the main weaknesses of the Aristotelian paradigm.

(C) 2004 Elsevier Ltd. All rights reserved.
\end{abstract}

Keywords: Aristotle; Eubulides; Logical paradoxes; Semantics

\section{Introduction}

Eubulides was a Greek philosopher in the fourth century BC, and is the almost forgotten author of four so-called 'paradoxes', the Liar, Electra, Sorites and the Horns. Although these paradoxes pose extremely serious problems for Aristotle's theory of truth, and consequently for modern semantics and logic, their significance has been underrated through the ages, probably because no answers were found.

E-mail address: pieter.seuren@mpi.nl (P.A.M. Seuren). 
They were often depicted as flippant cracks, unworthy of serious attention, but also sometimes as embarrassing riddles. During the 20th century these four problems have come up again. Indeed, one may say that they define, more or less, the whole research programme of 20th-century semantics. Yet the lineage to Antiquity has been acknowledged only for the Liar and Sorites. Electra and the Horns have been rediscovered (mainly by Frege), and there appears to be no awareness that they were part of the package of arguments put together by Eubulides. It now seems time, therefore, for a radical reappraisal and a rehabilitation of Eubulides as one who grasped and formulated the central problems of 20th-century semantics over 22 centuries earlier.

\section{The life and times of Eubulides}

Who was Eubulides? In actual fact, very little is known about his life and works. ${ }^{1}$ His exact date of birth is not known, but as an educated guess it may be placed towards the end of the fifth century, perhaps around $405 \mathrm{BC}$. We know that he was born in the Greek colony Miletus, in Asia Minor which is now known as Turkey. We know that as a young man he migrated to Greece, and that he took over a small school of philosophy in Megara, not far from Athens, in 380. According to the Oxford Classical Dictionary (s.v. Eubulides), 'he is said to have taught the Athenian rhetor Demosthenes dialectic [i.e. logic P.S.] and rhetoric', an important detail against the background of his well-known quarrels with Aristotle: Demosthenes was Athens' political leader in the struggle against the Macedonian king Philip II, and thus politically opposed to the Macedonian philosopher Artistotle, who taught in Athens from 335 to $323 \mathrm{BC}$, under the protection of Macedonian rule. It is not known exactly when Eubulides died, but one may surmise that it will have occurred some time around 330 BC. Eubulides is mainly known for his four 'paradoxes', till recently generally considered pointless or even flippant. Kneale and Kneale (1962, pp. 114-115), however, suspect that 'he must surely have been trying to illustrate some theses of Megarian philosophy', and that 'the Megarian study of the paradoxes was a serious affair and not mere perversity.' In the context of modern semantics, we now understand that Eubulides was criticising Aristotle, in particular the basic premisses of Aristotelian truth theory and logic, viz. truth as correspondence and the principles of Contradiction and of Bivalence. It is on account of his paradoxes that a total reappraisal of Eubulides is called for.

Let us first lend some colour to the historical setting in which we encounter Eubulides. His city of birth, Miletus, was one of the cities founded by the Greeks for the purpose of maritime trade. Like almost all Greek foundations on the coasts of Asia Minor, and also on the Sicilian and Southern Italian coasts, it had become rich and powerful well before the cities in metropolitan Greece reached their heyday. One does not have to be a Marxist to surmise that the early rise of philosophy in the

\footnotetext{
${ }^{1}$ The following reconstruction of Eubulides' biography implies a correction of Seuren (1998, p. 426).
} 
Greek colonies of Asia Minor, Sicily and Southern Italy was one of the side effects of the economic well-being of these cities. The sixth century philosophers Thales, Anaximander and Anaximenes were from Miletus. Heraclitus, who lived from \pm 535 till 480, was from Ephesus, also in Asia Minor. Pythagoras, though born in Samos around 580, taught at Croton in Southern Italy. The city of Elea, also in Southern Italy, had an important school of philosophy during the sixth and fifth centuries. Empedocles (483-423) was from Agrigentum in Sicily and taught philosophy there. It is therefore not surprising to see a young man from Miletus turn to philosophy during the early years of the fourth century.

Meanwhile, philosophy was beginning to develop in Greece proper, but in a very different vein. Whereas the earlier philosophers in the colonies had concentrated on questions of time, infinity and numbers, of the unity of physical matter, and the forces in the physical universe, the philosophers who began to appear in metropolitan Greece after about 450 took a wholly different, much more practical, direction. Most of them originated from the colonies, but they practiced in Greece proper as teachers on questions of political power, morality and truth, with a strong admixture of rhetoric. Again, one does not have to be a Marxist to see a connection between this change in focus and the rise of the first democracies in Greece proper (but not in the colonies, which all stayed under totalitarian rule). Since the early years of the fifth century, many Greek cities had assumed a form of government where decisions were taken in the people's assembly, consisting of free male adults of a certain economic standing. Clearly, in such a setting, it was important for ambitious youngsters to be able to sway public opinion in the political gatherings of their city state. To satisfy this demand, a number of men began to advertise themselves as teachers of rhetoric, political theory and whatever was available in the way of relevant knowledge in those days. These teachers, who were called 'Sophists' (literally 'experts'), travelled from city state to city state, offering their teaching for good money.

Not too much is known about the Sophists, as none of their writings have survived. All we know about them is based on secondary sources, i.e. quotations and comments by later authors, who vary in their judgments on the quality and moral standing of these itinerant teachers. The careful piecing together of all the evidence by modern scholars has resulted in a mixed overall picture. Whereas some of the Sophists, apparently, deserved a reputation of being a trifle too opportunistic, others stand out as intellectuals of high academic and moral standing.

When the best of them taught their young charges how to convince a public assembly by means of clever rhetoric, they also went into the question of the morality of doing so. One important question, obviously, was: may one tell the assembly falsehoods in order to gain power and influence? The answer was a guarded 'No'. But it was recognised, at the same time, that the question of what constitutes truth and falsity could not be answered satisfactorily. In the absence of any serious truth theory, the best they could do was make a democratic appeal to majority opinion: if the majority believes something to be true, then we may take it to be true (not unlike what is commonly seen in modern science). Similar questions arose as to norms of justice. Given the lack of absolute definitions of 'right' and 'wrong', each proposal to 
do with restrictions on personal freedom or with inflicting damage or punishment had to be judged on grounds of well-informed public opinion and a well-developed civic sense of justice and injustice. A good politician, therefore, had to be well-informed and share his knowledge with the citizens in the assembly, in order to come to a consensus on the best possible solution, given the circumstances. This was what the best of Sophist teaching amounted to. It is easy to see what Sophist teaching of less high standing would have been like.

One man in Athens, however, felt unhappy with this type of reasoning. This was the famous Socrates (469-399), an eccentric who went along the stalls of traders and craftsmen in the market, interrogating them about the philosophical foundations of their trade (and not making himself popular by doing so). Especially towards the end of his life, Socrates gathered a circle of mostly upper class young men around him, inspiring them with his questions and his analyses. One of these was Plato (429-347), whose family belonged to the old Athenian aristocracy. Unlike Socrates, who never wrote, Plato was a gifted and prolific writer. His philosophical dialogues, always figuring Socrates as a protagonist, occasionally reach the highest peaks of literary excellence.

The story of Socrates and his circle of admirers, including Plato, is a classic in our history books. It has been told and retold endless times, usually in admiring and often even romanticising tones. What was, however, usually either left out or definitely understressed, until Popper (1945) and Stone (1988), was the political side of things. Socrates, who was himself of what we would now call lower middle class origin, held ideas that were not typical of his class. He liked to associate with the antidemocratic, conservative upper class, which was one of the factors that united him with his circle of upper-class, conservative young followers. Stone, in particular, shows in minute detail the basically totalitarian attitude of Socrates, who favoured benevolent but absolute power on the part of one leader or a small group of leaders. Popper, half a century ago, made the world fully aware of Plato's political ideas: Plato actively propagated ruthless dictatorship, with a secret police, a ban on literature and travelling, a stifling of public debate, and all the other grim features of dictatorial regimes that we have come to know so well during the past century. Although Popper was scorned, and Stone largely ignored, by the community of ancient historians, their important contributions to our way of looking at this episode in history have gradually been accepted and integrated, and it is now no longer anathema to mention these more controversial aspects of early Athenian philosophy.

It is important to know this, because for a brief period of 14 months, between 404 and $403 \mathrm{BC}$, the democratic system of government in Athens was overthrown by a group of dictators, the so-called 'Thirty Tyrants'. The leader of the group was Critias, who belonged to Socrates' circle and was a first cousin of Plato's mother. Critias and his associates were responsible for over a thousand political murders and other atrocities committed during the year their regime lasted. Democracy was restored in the summer of 403, but the wounds remained. It is Stone's merit to have shown that the trial of Socrates, in 399, was part of the process, on the part of the democrats, of coming clean with the past without causing too much social damage. Socrates was convicted nominally on charges of 'corruption of youth', but in fact he 
was a scapegoat for the antidemocratic movement that had led to the tyranny of the Thirty. Socrates drank the hemlock and Plato fled Athens with a group of friends to live in exile. Not until 387 did Plato return to his native city, where he became highly respected and taught philosophy in his Academy till his death in 347.

Among Plato's students in the Academy, in fact the most prominent among them, was a young man called Aristotle. Aristotle was not from Greece but from Macedonia, a kingdom just north of Greece with a rough and uncivilised tradition but now rapidly assimilating Greek culture along with the Greek language. Aristotle was born in Stagira, not far from the capital Pella, in 384 BC. His father had been the personal physician and a close friend of the then king of Macedonia, Amyntas II. An exceptionally gifted boy to begin with, Aristotle joined Plato's Academy at the age of 17, to remain there till Plato's death in 347. Having been passed over as Plato's successor, he left Athens to live, first, in Asia Minor and then in Lesbos. In 343-342 Amyntas' son and successor, Philip II of Macedonia, invited him to come and teach his son Alexander, then 14 years old. This he did for two years, taking Alexander and a group of his friends to a mountain farm and teaching them all there was to know in those days.

During the 23 years of his reign, Philip had one great ambition, the conquest of Greece. Yet, despite many campaigns and battles, he never succeeded completely. Strong political opposition, especially on the part of the Athenians, and endless revolts kept frustrating his efforts. His main opponent in Athens was Demosthenes (384-322), who managed to inspire the Athenians, through his rhetorical skills, to keep resisting Macedonian domination.

In 336 BC Philip II was murdered and Alexander succeeded him, barely 20 years old. Already an army commander of unusual skill, he first completed the task his father had set himself but had failed to bring to an end, the conquest of Greece. In less than a year Alexander gained control of the whole of Greece, having set the total destruction of Thebes, ally of Athens, as a terrible example. After that, as one knows, he crossed into Asia and became master of the entire Middle East, getting as far as the Indus. In April 323, at the age of 33, he died in Babylon, one of the capitals of the Persian empire which he had conquered. By then he had become a legend if ever there was one. In Asia he was widely worshipped as a god. In Greece one was simply awed and baffled. He entered history as Alexander the Great, the source of a rich mythology through the remainder of Antiquity and the Middle Ages.

Meanwhile, Aristotle returned to Athens in 335, a year after his former pupil Alexander had established Macedonian rule there. Aristotle founded his own school of philosophy, the Lyceum, called after an ancient grove dedicated to Apollo Lyceios north-east of Athens (the site has recently been discovered and is now being excavated). There he taught till 323, when news of Alexander's death reached Athens. No longer certain of Macedonian protection, he left Athens overnight and sought refuge in Chalcis, just north of Athens, where a Macedonian garrison was stationed. One year later, in 322, he died of an intestinal disease.

Now back to Eubulides. No doubt attracted by the fame of Socrates and Plato, Eubulides migrated to Athens as a young man, and in or around 380 he took over a small but respectable school of philosophy that had been founded by a philosopher 
called Euclides (not the mathematician!) in the town of Megara, some thirty miles west of Athens. This Euclides is reported to have provided hospitality to Plato and his friends as they fled from Athens in 399, after Socrates' death. As was said at the beginning, tradition has it that Eubulides taught logic and rhetoric to the Athenian Demosthenes, the great opponent of Philip of Macedonia.

The evidence is scanty, but it suggests that the well-known personal animosity between Aristotle and Eubulides was at least partly also rooted in political differences. It is hardly thinkable that anti-Macedonian feelings had suddenly subsided after Alexander's forced entry in Athens. It is known, moreover, that Aristotle could only teach in Athens as long as he was protected by Macedonian power. The conclusion seems justified, therefore, that there must have been a strong anti-Macedonian faction in Athens and elsewhere in Greece throughout the period in question. And we may add that Eubulides was no doubt an ardent member of that faction. In any case, no sympathy was lost between him and Aristotle.

\section{The Aristotelian theory of truth}

But it is time now to turn to the real issues. One of the recurrent themes in Plato's dialogues, and probably also in Socrates' teachings, is the question of the nature of truth and falsity, broached by the Sophists. One of the things that worried Socrates and his followers was the fact that the Sophists presupposed an absolute notion of truth, even if adequate knowledge of what is true and false is often not attainable. If that is so, they reasoned, we must try and find out what truth, taken in and by itself, amounts to. Thus began the quest for the nature of truth and falsity. The theme recurs in many of Plato's dialogues, but it is treated most systematically in his dialogue The Sophist, written in his later years. Here, however, no clear and final conclusion is reached. Yet Plato makes some important statements, which have become integrated into the philosophical tradition. In Sophist (263B), we witness a little exchange between the Eleatic Stranger (ES) and the young Athenian Theaetetus (Th):

ES And the true sentence says the things about you the way they are.

Th What else?

ES And the false one says things that differ from the way they are.

Th Yes.

ES That is, it says things that are not, as if they were.

Th More or less, yes.

Here Plato states that truth consists in correspondence between what is said and what is the case, while falsity consists in presenting a state of affairs that differs from what is the case.

This notion of correspondence was further elaborated by Aristotle. After all the equivocations and inconclusive debates of the preceding century, Aristotle wants to be done with this question, and get on with things, such as the development of a 
proper truth calculus or logic. Early on in his Metaphysics, at $1011^{\mathrm{b}} 26$, he curtly defines truth as follows (translation by Warrington (Aristotle, 1956, p. 142)):

We begin by defining truth and falsehood. Falsehood consists in saying of that which is that it is not, or of that which is not that it is. Truth consists in saying of that which is that it is, or of that which is not that it is not.

We see that, remarkably, Aristotle does more than repeat Plato's correspondence criterion. He introduces a new element, the definition of not as a simple truthfunctional inverter of truth values: a toggle between true and false. This has momentous consequences.

We must have a closer look at the issues involved, since this is where Eubulides attacked him, as we shall see presently. In his Posterior Analytics (77 10-24), Aristotle presents, with great emphasis and insistence, two axioms ('no proof can be provided') for his truth theory, which are also applied in his logic. The first axiom is the Principle of Contradiction or PoC, which says that nothing can be the case and not be the case at the same time. It follows that no sentence can be true and false at the same time. The second axiom is the Principle of Bivalence or $\mathrm{PoB}$, or the Principle of the Excluded Third or PET. This says that propositions expressed in sentences fall into two (mutually exclusive) classes: the true ones and the false ones. A proposition is the mental act of assigning a property (accidens) to an entity (suppositum). This mental act can be expressed as a well-formed sentence in a language, whose subject term refers to the entity or suppositum in question, and whose predicate expresses the property assigned to the suppositum. Sentences that express a proposition, says Aristotle, have no choice but to be either true or false, with nothing in between and nothing outside these two values.

Aristotle places particular emphasis on his thesis that the opposition between truth and falsity is not gradual but absolute. In many other cases of opposite pairs there is a gradual transition from one extreme to the other, as with good and bad, or light and dark. But for him, true and false do not belong to this class of gradual opposites, but to the class of absolute opposites, like dead and alive (for entities that have biological life), or even and odd (for numbers). This is his Principle of the Excluded Middle or PEM. It applies absolutely, but for one reservation. In On Interpretation $19^{\text {a } 30}$ Aristotle discusses the problem of the sea battle which is going to take place, and he then makes a possible exception for statements about future events, which would be exempted from PET. Otherwise, however, PET applies absolutely.

Although PEM and PET are often confused, even in respectable writings, one can easily see that PEM is only a subaxiom of the more general PET. The other subaxiom, which we may call the Binarity Principle or BP, is Aristotle's thesis that there are exactly two truth values, and not three or even more.

This yields the following rendering of Aristotle's truth theory, applied in his logic:

Axioms: (I) Principle of Contradiction $(\mathrm{PoC})$

(II) Principle of Bivalence $(\mathrm{PoB})$ or Principle of the Excluded Third (PET) 
Subaxioms: (a) Principle of the Excluded Middle (PEM)

(b) Binarity Principle (BP)

But there is more. If truth consists in correspondence between what is said and what is actually the case, that is, if truth is found in the linguistic expression of a proposition that mentally assigns to an entity a property which the entity really has, in the actual world, then it should make no difference for the truth or falsity of an uttered sentence what expression is used to refer to the entity in question, or what expression is used to denote the property in question. What matters is only that the referring expression does indeed successfully refer to the entity intended, and that the predicate expression does indeed denote the property which the speaker has in mind. In other words, it is a direct consequence of Aristotle's notion of truth as correspondence that referring terms or predicate expressions may be substituted for each other salva veritate (i.e. without affecting the truth value) provided the terms refer to the same entity and the predicate expressions denote the same property.

This consequence was known to Aristotle but he did not subject it to closer scrutiny. It was not until Leibniz (1646-1716) that it was actually formulated as a principle. Leibniz gives a variety of wordings, the best known of which is probably (Gerhardt, 1890, p. 228):

Eadem sunt quorum unum potest substitui alteri salva veritate.

or 'If two terms can stand in for each other salva veritate, their reference is identical'. This has since become known as the Principle of Substitutivity, fundamental in modern semantics.

\section{The Eubulidean paradoxes}

\subsection{The paradoxes and Aristotle}

But what has all this to do with Eubulides? The answer is simple. Eubulides is mainly known, in what little there is about him in the literature, for his so-called paradoxes. The Greek author Diogenes Laertius (early 3rd century AD), an invaluable source of information about ancient philosophy, writes (ii, 108):

Among the successors of Euclides was also Eubulides, who raised many questions of logic: the liar, the unnoticed man, the Electra, the hooded man, the heap, the horned man, and the bald man.

In Kneale and Kneale (1962, p. 114) we read:

From the explanations given by various writers of later antiquity it appears that some of the seven paradoxes specifically attributed to Eubulides were 
merely variants of others and that the list can probably be reduced to the four following items:

(1) The Liar. 'A man says that he is lying. Is what he says true or false?'

(2) The Hooded Man, the Unnoticed Man, or the Electra. 'You say you know your brother. But that man who came in just now with his head covered is your brother, and you did not know him.'

(3) The bald man, or the Heap. 'Would you say that a man was bald if he had only one hair? Yes. Would you say that a man was bald if he had only two hairs? Yes. Would you..., etc. Then where do you draw the line?'

(4) The Horned Man. 'What you have not lost you still have. But you have not lost your horns. So you still have horns.'

This is explosive stuff for Aristotle's theory of truth. According to Kneale and Kneale (1962, p. 228), Aristotle himself was aware of the paradoxes (e.g. De Sophisticis Elenchis $180^{\mathrm{b}} 2-7$ ), and he was certainly sharp enough to have seen the deadly power of the arguments. But he declined to answer. This is remarkable, because he did reply to other criticisms directed at him by the Megarians, for example on modalities, or on the distinction between acting and undergoing. In those cases his comment is invariably that the Megarian point of view is 'silly' (Greek átopon). But he never replied to the paradoxes put forth by Eubulides. One may well surmise, therefore, that Aristotle simply had no reply.

\subsection{The Liar paradox}

The Liar paradox is, of course, very well known nowadays. Its simplest form is in the sentence What I am saying now is false. Anyone saying this gets into trouble, for if what is said is true, it is at the same time false, and if it is false, then it is at the same time true. It looks very much as if this paradox undermines both Aristotle's Principle of Contradiction and his Principle of Bivalence, since it appears to lead to the conclusion that sentences such as the one just given can be both true and false at the same time, which means that there would, after all, be a third possibility not catered for in Aristotle's theory of truth. Clearly, no-one will seriously propose this as a reasonable alternative to the Aristotelian theory, but if that theory is to be saved, then a satisfactory answer must be given to this paradox.

In Antiquity, the Liar paradox was well-known, but nothing much was done about it. Cicero was well aware of the Liar paradox, and of the others as well. In Academicae Quaestiones (ii, 96) he formulates the paradox, but attributes it wrongly to Chrysippus, a later Stoic philosopher:

If you say that you lie and you speak the truth, you lie. But then you say that you lie and you speak the truth, so you lie. This question was raised by Chrysippus, but not solved by him. 
In his De Divinatione (ii, 11) Cicero mentions the Liar paradox along with the Sorites ('heap'):

Can anything of what is dealt with by logicians or physicists be solved by soothsaying? Whether there is one world or many, what the first beginnings were of the world, from which everything originated: those are questions that come within the physicists' competence. And how to solve the Liar, also called by the Greek name of Pseudomenon, or the Sorites (which one may call the Acervalis ['heap'] in Latin if one finds that necessary, but it isn't necessary because the very word philosophia and many other Greek words, such as Sorites, have gained currency in Latin): those are questions for the logicians, not the soothsayers.

And many other references to the Liar and the other paradoxes are found in the literature.

A weak but famous reflex is found in Paul's Epistle to Titus (I, 12-13), where Paul, cursing the Cretans, writes, obviously unaware of the problem:

One of themselves, even a prophet of their own, said, The Cretians are always liars, evil beasts, slow bellies. This witness is true.

The 'prophet' referred to is a Cretan poet, Epimenides (6th century BC), which is why the paradox is also often called the Epimenidan paradox. Strictly speaking, however, this is not paradoxical. It is sufficient to assume that the Cretan 'prophet' Epimenides simply said a falsehood if he said that all Cretans always lie. The problem arises only if one makes him speak the truth, as Paul does. In that case, there is indeed a problem, because then Epimenides allegedly spoke the truth and at the same time, being a Cretan himself, must have lied.

Perhaps due to this passage in Paul's letter to Titus, the Liar paradox became very popular in medieval philosophy from the 12th century onward. The term used for the paradoxes, especially the Liar, was insolubilia ('unsolvables'). Kneale and Kneale (1962, p. 228) write:

[S]o far little work has been done on the surviving texts, and we cannot even say yet when or how the study of insolubilia began....

It may be... that the [Liar] paradox was discovered afresh in the 12th century. In any case medieval logicians were not satisfied with simple versions such as Ego dico falsum, but invented complicated variants like "Socrates says "What Plato says is false", and Plato says "What Socrates says is true", and neither says anything else. Is what Socrates says true or false?' It was realized that the trouble arose from the attempt to produce a certain sort of self-reference, and an insolubile was defined as a 'propositio habens super se reflexionem suae falsitatis aut se non esse veram totaliter vel partialiter illativa.' But there was no single agreed doctrine about the bearing of such paradoxes on the theory of 
meaning and truth. On the contrary, various medieval logicians suggested various ways of dealing with the trouble.

Kneale and Kneale then mention an anonymous manuscript (Bibliothèque Nationale, Cod. Lat. 16617) probably dating from the early 14th century, where three possible solutions to the Liar are discussed. One solution is called restrictio and consists in a simple prohibition of token reflexivity (self-reference) in the use of language. Another solution proposed is that of cassatio or nullity of meaning. This implies that sentences or texts that suffer from the Liar paradox are uninterpretable due to the impossibility of identifying an entity (suppositum) for the subject term in a Liar sentence like This very sentence is false. The third solution, cryptically called 'secundum quid et simpliciter', is (Kneale and Kneale, ib.), 'an unsatisfactory suggestion extracted from the passage of Aristotle mentioned above' [i.e. De Sophisticis Elenchis $\left.180^{\mathrm{b}} 2-7\right]$.

The solution proposed by Russell and Tarski in our century is a modern form of restrictio, and it is now considered the standard solution to the Liar paradox. Yet, although it seems to work satisfactorily in logical languages, which can be subjected to restrictions like a prohibition to mix object language and metalanguage, in natural language, as Kneale and Kneale rightly observe (1962, p. 228), this would exclude all sorts of harmless forms of self-reference, such as What I am now saying is a sentence of English. In fact, one may add, natural language use is replete with perfectly natural and harmless mixings of object language and metalanguage, which, of course, nobody is going to forbid. A simple example is:

(1) Jones has lived in Dnjepropetrovsk for many years, but he can still not pronounce it

where it refers not to the city of Dnjepropetrovsk but to its name. It would seem, therefore, that the Kneales are right in rejecting this restrictio for the theory of natural language meaning.

Cassatio has hardly been explored in modern times, largely due to the dominant position of Russellian logic, which claims to have solved the Liar paradox definitely, completely disregarding the consequences of its solution for natural language. Yet we can easily pursue or reconstruct the cassatio argument. In a sentence like This very sentence is false the term this very sentence must refer to a proposition expressed, since the predicate false requires propositions to apply to. We thus need a proposition to serve as the suppositum of the predicate false. But all there is to be found is the very same proposition expressed, which is then again said to be false, and so on ad infinitum. There is thus no proposition to be found of which it can be said that it fails to satisfy the satisfaction conditions of the predicate false. ${ }^{2}$

The third solution mentioned in the medieval manuscript, secundum quid et simpliciter, does not appear to deserve further scrutiny.

\footnotetext{
${ }^{2}$ This argument is proposed as the correct solution for natural language in Seuren (1987/2001).
} 


\subsection{The Electra paradox}

Now to the second paradox, which we shall call the Electra, though it is also known as 'the Unnoticed Man' and 'the Hooded Man'. The mythical story, generally known, of course, in Eubulides' and Aristotle's day, goes as follows. While Agamemnon, king of Mycenes, was away to fight in the Trojan war, his wife Clytaemnestra had set up house with another man. Obviously, when Agamemnon was due back, there would be a problem. So when Agamemnon came home Clytaemnestra let him have a warm bath, during which she chopped his head off with a sword. That would have been the end of the affair, had it not been for the children, in particular the son Orestes, who now had the holy duty to avenge his father. However, in order to do that, he would have to kill his mother, which would be a heinous crime. In order to sort out his moral dilemma, Orestes went to stay with an uncle for a while. At the end of that period he has made up his mind and has decided that the right thing to do, after all, is to kill his mother. So he returns to Mycenes, but, sensibly fearing to receive a treatment similar to his father's, he disguises himself as a beggar so as not to be recognised. He then knocks at the gate and is let in. His sister Electra has him shown to the kitchen and given some soup. At this point in the story, Eubulides steps in and asks: 'Is the sentence Electra knows that her brother Orestes is in the kitchen true or false?' It should be true, since she knows that the beggar is in the kitchen, and the beggar is identical with Orestes. Therefore, given the Principle of Substitutivity mentioned above, Electra should also know that Orestes is in the kitchen. Yet she obviously does not know that, because if she did she might well have raised the alarm. We see here that the Principle of Substitutivity apparently does not always apply, and the question is why not.

Aristotle may have seen that this is a very serious threat to his theory of truth, but there is no record of any reply. Nor is there any record through the ages of a proper analysis of the Electra paradox in the context of Aristotelian truth theory, until Frege (1892), who rediscovered the problem but was apparently unaware of its history in the Electra paradox.

Frege found, first, that substitution of coreferring terms in identity statements complicates Aristotelian truth theory. In the true identity statement:

(2) The morning star is the evening star

the terms the morning star and the evening star both refer to the same entity, the planet Venus. Here, substitution of one term for the other, as in:

(3) The morning star is the morning star

will not change the truth value of the sentence, but it adds the peculiarity that the sentence then becomes necessarily true, i.e. true in all possible situations, given the metaphysical axiom that everything is identical to itself. In contrast, (2) is a contingent statement, reporting a discovery that was made some time in the distant past (probably by the Greeks).

His solution consisted in an application of the old distinction between intension and extension not just to predicates, for which it was invented in medieval philos- 
ophy, but also to definite terms. Frege now stipulates that the extension (or reference) of a term is the entity referred to, while the intension (or sense) of a term is 'the way in which it is presented' ('die Art des Gegebenseins', p. 26), or, in other words, the procedure by which the listener arrives at the entity referred to, given the term in question. ${ }^{3}$ Now, Frege says, the terms the morning star and the evening star have the same extension, but different intensions. This explains that (2) is a contingent statement, since when two different paths are followed it may come as a surprise that they lead to the same point, while (3), where the same path is followed twice and thus the same point is reached twice, is a necessary truth.

Our interest, however, lies in Frege's second finding. Like Eubulides, he found that substitutivity actually fails in what he called 'oblique' ('ungerade') contexts. That is, when a sentence or clause is embedded (usually as a that-clause) under a predicate that assigns a property to thoughts as entities, then substitution of coreferring terms may well lead to different truth values. Frege gives precious few examples, but his meaning is clear enough. Consider:

(4) a. Jones believes that there is life on the morning star.

b. Jones believes that there is life on the evening star.

If Jones does not believe that the morning star is identical with the evening star, (4a) may well be true and (4b) false, or vice versa. The parallel with the Electra paradox is obvious:

(5) a. Electra knows that the beggar is in the kitchen.

b. Electra knows that her brother Orestes is in the kitchen.

Since Electra does not know that the beggar is identical with her brother Orestes, (5a) is true but (5b) is false (in the story).

It was clear to Frege, and one may hope also to Eubulides and to Aristotle, that this failure of substitutivity in what we now call intensional contexts poses a serious threat to the Aristotelian theory of truth, which entails substitutivity. An answer is therefore absolutely necessary. Frege's answer consisted in extending the extensionintension distinction to sentences and clauses as well. For him, the extension of a sentence is its truth value, while its intension is the underlying thought expressed in the sentence. For him the following two sentences:

(6) a. There is life on the morning star.

b. There is life on the evening star

have the same extension (truth value) but different intensions (underlying thoughts).

\footnotetext{
${ }^{3}$ Cp. Dummett (1973, p. 281): 'In Frege's theory, the sense of a name consists of the means we have provided for determining an actual (existent) object as its referent.'
} 
However, when a sentence is embedded under a predicate assigning a property to thoughts, such as believe or know, the embedded clause is an argument term of the predicate and refers to a thought, not to a truth value. Now it follows that the that-clauses in (4a) and (4b), or (5a) and (5b), refer to different thoughts, which means that substitution of one that-clause for another does not guarantee the preservation of the truth value of the whole sentence. It follows that substitutivity of terms which in fact corefer must fail in intensional contexts, which involve a subject that may not be aware of the fact that the two terms corefer.

Frege's solution appealed to modern logicians. Yet when they began to develop what is known as 'formal semantics', around 1950, the notion 'thought' was considered suspect and unmanageable in a formal context. It was for that reason that Frege's solution to his second problem, the failure of substitutivity in intensional contexts, was reformulated in terms of a model-theoretic calculus involving possible worlds. We shall not go into the details of the theory of formal semantics, but it will be clear that Frege's second problem, which is, in fact, the Electra paradox, has been crucial in its development. And since, rightly or wrongly, formal semantics has dominated semantic studies since the early 1970s, we may say that the Electra paradox is at the very centre of modern semantic theory. Yet there is not a single mention of this fact in the literature. All references are to Frege, and Eubulides has been totally forgotten.

\subsection{The Sorites}

The third paradox, generally known under the name of Sorites (from Greek sorós 'heap'), but also known as 'the Bald Man', is a direct attack on the Aristotelian Principle of the Excluded Middle (PEM). It says, in effect, that the opposition between truth and falsity is like that between light and darkness: there are infinitely many intermediate values between the two extremes. This is embarrassing for the Aristotelian truth theory, since if truth consists in correspondence between what is said (or thought) on the one hand and that which is the case on the other, then, one would have thought, there is correspondence or there is not. There is no way in between.

Nowadays, however, many philosophers and linguists feel that a different look at what constitutes truth easily undermines this argument. If truth is seen not as correspondence but rather as the result of the satisfaction of the conditions set by the predicate of the sentence (proposition) in question by the entity or entities referred to by the term(s), then PEM is no longer a necessary consequence of the truth theory. For the satisfaction conditions of predicates may themselves leave room for partial fulfilment. The predicate dark, for example, is fully satisfied when there is no light at all, but it is partially satisfied when there is a little light, but not enough to justify the predicate light for the entity referred to by the subject term. Thus, one may say that a sentence like This room is dark is partially true of a room where there is just a little light, or that This man is bald is partially true of a man with just a few hairs on his head. 
Predicates like dark or light are called 'vague' predicates, and it will be clear that natural languages contain large masses of them. A number of theories have been developed during the 20th century, both in logic and in semantics, to account for this kind of vagueness. Best known are the logical approaches. The Polish logician Lukasiewicz devised a three-valued logic, where the third value is to be considered intermediate between truth and falsity. In Lukasiewicz (1930) it is shown that the intermediate value ('1/2') can be extended to encapsulate all denumerably infinite intermediate values, so that this logic may be taken, in a certain sense (not intended by Łukasiewicz himself, who applied his logic to modalities) to account for a denumerable infinity of intermediate values that may arise with vague predicates. The same logic, as far as negation, conjunction and disjunction are concerned (but with a different material implication), is used in Kleene (1952). The 'fuzzy' logic presented in Zadeh (1975) is more radical, in that it is based on a 'fuzzy' set theory and implies a non-denumerable infinity of intermediate values (see Haack, 1978, p. 165 for further comment).

Again, we shall leave the technical details aside, but it is clear that the Sorites has had a important impact on modern semantic and logical studies. In this case, the name 'Sorites' has not been forgotten. In fact, it is a standard reference in the vagueness literature. Yet hardly any author seems to realize that the Sorites was first formulated by Eubulides as a contemporary attack on Aristotle's truth theory, and in the context of other similar attacks.

\subsection{The paradox of the horns}

We now come to the last of the four paradoxes. It consists of the following logical riddle:

What is wrong with the following argument?

Major: What you haven't lost you still have.

Minor: You have not lost your horns.

Ergo: You still have your horns.

Besides the somewhat scurrilous aspect of the example, which would almost certainly have irritated Aristotle (never known for his sense of humour), there is the logical problem: if the argument is correct, then everyone could be rightly branded as either a present or a former cuckold.

We now know that this riddle shows up the presupposition problem, which has still not found a generally accepted solution in either logic or semantics (or pragmatics). The problem is that presuppositions are normally preserved under negation, but that it is often possible to deny the presuppositions as well. This presupposition-cancelling negation is subject to certain conditions, for example that the negation has to be a separate word (not a bound morpheme), must be used emphatically and (for English) constructed with the finite verb form. There are thus (at least) two different possible uses of the negation, in English as in Greek, with differing truth-conditional properties. 
The sentence You have lost your horns carries the presupposition that the addressee once had horns. This presupposition derives from the satisfaction conditions (meaning) of the predicate have lost, which requires that what has been lost must once have been possessed (just like what has been forgotten must once have been known, or whoever is back, must once have been away). If this sentence is made negative in the normal, presupposition-preserving way, we get You haven't lost your horns, which still presupposes that the addressee once had horns. The sentence presented in the Major of the argument, What you haven't lost you still have, expresses the general statement that in all cases, if one hasn't lost Y, one still has Y. This general statement is based on the presupposition that goes with sentences of the type $X$ has lost $Y$, and on the interpretation of the negation $n$ ' $t$ as presuppositionpreserving.

Again, in the sentence presented in the Minor of the argument, the word not is used ambiguously, since it is not clear whether this is the presupposition-preserving or the presupposition-cancelling (use of the) negation. So the argument is valid (and the addressee is a cuckold) only if both negations, in the Major and the Minor, are interpreted as presupposition-preserving. But if not in the Minor is taken as the presupposition-cancelling not, then the argument is not valid, and the addressee need not worry. This is the answer that Aristotle could have given but didn't, probably because he was, like Strawson in his (1950), unaware of the possibility of presupposition-cancelling not.

Not much is known about the presupposition problem in either Antiquity or the Middle Ages. We now know that the solution to Eubulides' paradox of the Horns lies in an adequate analysis of presuppositions, but there are no signs that Eubulides himself was aware of that fact. Nor do we see the issue raised in any of the Ancient literature on logic or the philosophy of language. The same goes for the medievals. Occasionally, however, they came close. In an anonymous treatise, Ars Meliduna, dated around 1170 (Nuchelmans, 1973, p. 165), Aristotle's celebrated Bivalence Principle is called into question. One of the grounds for doubt in this respect consists in the fact that utterances may be neither true nor false but nugatory, as one reads in De Rijk's edition of the treatise (De Rijk, 1967, p. 363):

... enuntiables such as that 'Socrates is white because it is him' or that 'he loves his son' appear to become nugatory when Socrates is no longer white or no longer has a son. We must, therefore, posit that such enuntiables may become nugatory even if that goes against Aristotle...

Since most of the examples mentioned in the Ars Meliduna are to do with cases of what we now recognise as presupposition, Nuchelmans writes (1973, p. 174):

[T]he sentence as such does not have a definite truth-value unless certain presuppositions are fulfilled. Only if the situation is such that the thing asserted by the sentence in general fits into it does the enuntiabile come to have a definite truth-value; otherwise it does not make contact with features of reality which are capable of rendering it either true or false. 
No attempt, however, is made in this treatise to investigate the condition of being 'nugatory' as a result of given contextual conditions.

Some confusion has been caused by Horn's observation (1985, p. 123; 1996, p. 300 and elsewhere) that the term praesupponere occurs in a text called Tractatus Exponibilium (Mullally, 1945, p. 112), which he, following Mullally (1945), incorrectly attributes to Peter of Spain $( \pm 1212-1277)$, the later Pope John XXI. ${ }^{4}$ Horn takes over Mullally's translation 'presuppose'. But again, this cannot be correct. The term is used in the context of a sentence type called 'reduplicatives', such as: insofar as man is rational, he is capable of weeping. My best translation of the passage is:

The first rule is that a reduplicative word anticipates (praesupponit) that some predicate inheres in some subject [i.e. thing] and means (denotat) that that [i.e. the clause] to which it is immediately attached is [i.e. expresses] the cause of that inherence.

That is, the expression insofar as anticipates that some predicate ('capable of weeping') inheres in some subject ('man'), and means that 'insofar as man is rational' expresses the cause of man's being capable of weeping. Since there can be no question of 'man is capable of weeping' being presupposed by the sentence mentioned, we must conclude that praesupponere is used here in a different sense from what presuppose means today. As a matter of fact, the word does not occur anywhere else in the whole of the philosophical literature written in Latin.

Apart from this misunderstanding, however, the main authors, other than the anonymous author of the 12th-century Ars Meliduna, that have been found discussing phenomena of a presuppositional nature (but without using the term praesupponere) are the 12th-century Frenchman Peter Abelard (De Rijk, 1956), the 13th-century Portuguese Peter of Spain (De Rijk, 1972) and the 14th-century Englishman Walter Burleigh (De Rijk, 1985). They focus on the presupposition that comes with (the Latin equivalent of) only, as in (7a), and those that are induced by aspectual verbs like stop, as in (7b):

(7) a. Only the children laughed (presupp.: the children laughed).

b. Jones has stopped smoking (presupp.: Jones has once smoked).

To what extent the presupposition problem was a topic in medieval philosophy is not known. But it does seem as if the link with the Horns paradox had already been lost.

In modern times it is, again, not until Frege (1892) that the problem is rediscovered, and in a different shape and context. Frege does not deal with the presupposition problem specifically, but only mentions it in passing (1892, pp. 31-32), in a purely philosophical (metaphysical) context:

\footnotetext{
${ }^{4}$ According to De Rijk (1972, p. xcix) the Tractatus Exponibilium is certainly not by Peter of Spain, as it begins to crop up at the end of manuscripts of Peter of Spain's Summulae Logicales starting from about 1350 .
} 
Idealists and skeptics may already have objected: 'You simply talk [in the sentence 'The moon is smaller than the earth'] about the moon as if it were an object. But how do you know that the definite description 'the moon' has a referent at all? How do you know that anything has a referent?' My answer to this is that it is not our intention to speak of the mental representation of the moon, and that we likewise do not content ourselves with just the sense (meaning) when we speak of the moon. But we presuppose a referent.

... Now we may be wrong in assuming this presupposition, and such errors have indeed occurred in the past. But the question of whether we are always mistaken can remain unanswered here. It is sufficient to point to our intention when we speak or think, to justify our talk about the referent of a sign: there is always the reservation 'in case it really exists'. [italics mine, P.S.]

We see here that Frege is not concerned with presuppositions like those induced by only or by specific predicates like stop or have lost, but with presuppositions of existence, which he links up with the definite article the. Technically, Frege's problem is that if there is no referent (extension) for the (subject) term in question, there is no truth value (extension) for the sentence, since then there is no entity available to test if it satisfies the conditions set by the predicate. In this respect, Frege's account harbours the threat of a violation of Aristotelian bivalence.

The point was taken up again in Russell (1905), where Russell presents his famous Theory of [definite] Descriptions. In order to save Aristotelian truth theory and logic from this threat, Russell proposes that the logical analysis of sentences should never contain a definite determiner (article), and that all definite descriptions of the form the so-and-so should be dissolved into an existential quantifier and a few propositional functions. Thus, the sentence:

(8) The present king of France is bald

should be assigned the logical form (9a) or, in technical notation, (9b):

(9) a. There is an $\mathrm{x}$, such that $\mathrm{x}$ is king of France and $\mathrm{x}$ is bald, and for all $\mathrm{y}$, if $\mathrm{y}$ is king of France, $y$ is identical with $x$.

b. $\exists \mathrm{x}[\operatorname{KoF}(\mathrm{x}) \wedge \operatorname{Bald}(\mathrm{x}) \wedge \forall \mathrm{y}[\operatorname{KoF}(\mathrm{y}) \rightarrow \mathrm{y}=\mathrm{x}]]$

Now the negation of this sentence:

(10) The present king of France is not bald

does not imply that there is a king of France:

(11) a. Not [there is an $\mathrm{x}$, such that $\mathrm{x}$ is king of France and $\mathrm{x}$ is bald, and for all $\mathrm{y}$, if $\mathrm{y}$ is king of France, $\mathrm{y}$ is identical with $\mathrm{x}]$

b. $\neg \exists \mathrm{x}[\operatorname{KoF}(\mathrm{x}) \wedge \operatorname{Bald}(\mathrm{x}) \wedge \forall \mathrm{y}[\mathrm{KoF}(\mathrm{y}) \rightarrow \mathrm{y}=\mathrm{x}]]$ 
Unfortunately, however, says Russell, speakers of natural languages, for reasons best known to themselves, normally interpret (10) not as (11), as they should (and also do in exceptional cases), but as (12), with the negation covering only ' $\mathrm{x}$ is bald' or 'Bald( $\mathrm{x})$ ':

(12) a. There is an $x$, such that $x$ is king of France and not [ $x$ is bald], and for all $y$, if $\mathrm{y}$ is king of France, $\mathrm{y}$ is identical with $\mathrm{x}$

b. $\exists \mathrm{x}[\mathrm{KoF}(\mathrm{x}) \wedge \neg[\operatorname{Bald}(\mathrm{x})] \wedge \forall \mathrm{y}[\mathrm{KoF}(\mathrm{y}) \rightarrow \mathrm{y}=\mathrm{x}]]$.

In this interpretation, the existence of the king of France is entailed. But it is not the logical negation of (9). Thus, by the brutal destruction of grammatical structure and the invention of a logical analysis that does not fit the grammatical facts at all, Russell tried to save Aristotelian truth theory and the Aristotelian axiom of bivalence (PET).

Russell's rough handling of natural language was criticised by the Oxford philosopher Strawson (Strawson, 1950 and later publications). Strawson, restricting himself to existential presuppositions, felt that the Aristotelian PET should be given up in favour of a so-called gapped bivalent system with the values 'true', 'false', and 'undefined'. The value 'undefined' results when one or more presuppositions of a sentence are false. For him, the negation is per se presupposition-preserving, which gives the following truth-table for gapped bivalent not $(\sim)$ :

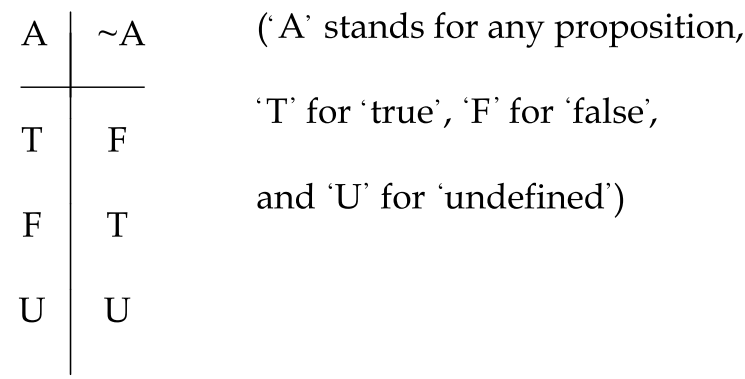

A great deal has been said and written about presuppositions and presuppositioncancelling since Strawson put forward his proposal. Later authors have extended Strawson's notion of presupposition to one that encompasses other types of presupposition as well, such as those that are induced by lexical satisfaction conditions, or words like only and even, etc. Various schools of thought have sprung up, in logic, semantics and pragmatics, all differing in their views of how presuppositions are best accounted for. It cannot be our purpose here to try and adjudicate upon this complex question, but it is clear that we have here a major development in the semantics and pragmatics of natural language. And here, too, we see that Eubulides had already got hold of the issue, and in a way that was critical of Aristotle.

\section{Conclusion}

The overall conclusion is that, in Aristotle's own day, Eubulides formulated four heavy arguments against Aristotle's theory of truth and therefore his strictly bivalent 
logic. These paradoxes or riddles were beyond the powers of philosophers and logicians for many centuries, and were consequently ridiculed by many, including Aristotle himself, although some did see their significance. Yet the historical awareness of their author and of the original context in which they were conceived was generally lost. It was only in the 20th century, in the context of the mathematisation of logic and of a renewed interest in natural language (formal) semantics, that the paradoxes of Eubulides were rediscovered and recognised for what they are: heavy broadsides on the Aristotelian paradigm. As was said at the outset, the four paradoxes more or less define the entire research programme of formal or formally oriented modern semantic studies. It is the purpose of this attempt at historical reconstruction to broaden the perspective of those who take an interest in the history and other backgrounds of the semantics, logic and pragmatics of natural language.

\section{References}

Aristotle, 1956. Metaphysics. Dent \& Sons, London. Edited \& translated by John Warrington.

De Rijk, L.M., 1956. Petrus Abaelardus Dialectica. First Complete Edition of the Parisian Manuscript. Van Gorcum/Hak \& Prakke, Assen.

De Rijk, L.M., 1967. Logica Modernorum. A Contribution to the History of Early Terminist Logic. Vol. II.1: The Origin and Early Development of the Theory of Supposition. Van Gorcum, Assen.

De Rijk, L.M., 1972. Peter of Spain (Petrus Hispanus Portugalensis) Tractatus, called afterwards Summule Logicales. Van Gorcum, Assen.

De Rijk, L.M., 1985. Walter Burley's tract 'De Exclusivis'. An edition. Vivarium 23, $23-54$.

Dummett, M., 1973. Frege. Philosophy of Language. Duckworth, London.

Frege, G., 1892. Ueber Sinn und Bedeutung. Zeitschrift für Philosophie und philosophische Kritik 100, $25-50$

Gerhardt, C.I., 1890. Die philosophischen Schriften von Gottfried Wilhelm Leibniz. Vol. VII. Olms Verlagsbuchhandlung, Hildesheim.

Haack, S., 1978. Philosophy of Logics. Cambridge University Press, Cambridge.

Horn, L.R., 1985. Metalinguistic negation and pragmatic ambiguity. Language 61, 121-174.

Horn, L.R., 1996. Presupposition and implicature. In: Lappin, S. (Ed.), The Handbook of Contemporary Semantic Theory. Blackwell, Oxford, pp. 299-319.

Kleene, S.C., 1952. Introduction to Metamathematics. North-Holland, Amsterdam.

Kneale, W., Kneale, M., 1962. The Development of Logic. Clarendon Press, Oxford.

Łukasiewicz, J., 1930. Philosophische Bemerkungen zu mehrwertigen Systemen des Aussagenkalküls. Comptes rendus des séances de la Société des Sciences et des Lettres de Varsovie, Cl. iii 23, 1-77 (English translation: 'Philosophical remarks on many-valued systems of propositional logic' in McCall (1967), pp. 40-65).

McCall, S. (Ed.), 1967. Polish Logic: 1920-1939. Clarendon Press, Oxford.

Mullally, J.P., 1945. The Summulae Logicales of Peter of Spain (= Publications in Medieval Studies viII) The University of Notre Dame Press, Indiana.

Nuchelmans, G., 1973. Theories of the Proposition. Ancient and Medieval Conceptions of the Bearers of Truth and Falsity. North-Holland, Amsterdam.

Popper, Karl R., 1945. The Open Society and its Enemies. Routledge \& Kegan Paul, London.

Russell, B., 1905. On denoting. Mind 14, 479-493.

Seuren, P.A.M., 1987. Les paradoxes et le langage. Logique et Analyse 30 (120), 365-383 (Reprinted as Chapter 6 in Seuren (2001)).

Seuren, P.A.M., 1998. Western Linguistics. An Historical Introduction. Blackwell, Oxford.

Seuren, P.A.M., 2001. A View of Language. Oxford University Press, Oxford. 
Stone, I.F., 1988. The Trial of Socrates. Jonathan Cape, London.

Strawson, P.F., 1950. On referring. Mind 59, 320-344.

Zadeh, L.A., 1975. Fuzzy logic and approximate reasoning. Synthese 30, 407-428. 